\title{
Cost-Benefit Computer Modeling of Helicobacter pylori Testing and Treatment in Patients on Long-Term $\mathrm{H}_{2}$-Blocker Prophylaxis
}

OBJECTIVE: To compare the various cost components of long-term $\mathrm{H}_{2^{-}}$ antagonist prophylaxis with coordinated Helicobacter pylori (H. pylori) screening and treatment in previously diagnosed peptic ulcer patients.

DESIGN: Using computer modeling, decision-tree analysis, published clinical probabilities, and direct Veterans Affairs medical costs, costs for $\mathrm{H}_{2}$ antagonist maintenance were compared to costs for $H$. pylori screening and treatment.

SETTING: Veterans Affairs San Diego Healthcare System (VASDHS).

PATIENTS: Patients previously diagnosed with peptic ulcer disease on long-term $\mathrm{H}_{2}$-antagonist prophylaxis.

MAIN OUTCOME MEASURES: Total health care costs for $\mathrm{H}_{2}$-antagonist maintenance compared to costs for $H$. pylori screening and treatment.
RESULTS: For the first year following implementation of an $\mathrm{H}$. pylori dedicated clinic with a test-and-treat approach, total health care cost savings including clinic costs are estimated to be $\$ 39,600$ at the VASDHS. Subsequent net cost savings would be $\$ 212,400$ at the end of year two and $\$ 368,100$ at the end of year three.

CONCLUSIONS: Preventing future ulcer recurrences with $H$. pylori eradication substantially reduces health care utilization. Cost analysis using the pharmacoeconomic model demonstrates long-term clinical and financial benefits associated with an $H$. pylori screening and treatment approach.

KEYWORDS: Pharmacoeconomic, ulcer, Helicobacter pylori, disease-state management, cost-benefit analysis, decision analysis, health screening

J Managed Care Pharm 2000: 383-89

\section{Authors}

GRACE T. JONE, Pharm. D., was Pharmacy Practice Resident with Geriatric Emphasis, Veterans Afjairs San Diego Healthcare System, San Diego, CA, at the time of this study; she is now Primary Care Pharmacist, Adult Medicine, Kaiser Foundation Health Plan in Pleasanton, CA. ANTHONY P. MORREALE, Pharm.D., M.B.A., B.C.PS., is Assistant Chiej of Pharmacy, Veterans Affairs San Diego Healtheare System.

AUTHOR CORRESPONDENCE: Grace T. Jone, Pharm D., Primary Care Pharmacist, Adult Meditine Department, Kaiser Foundation Health Plan, 7601 Stoneridge Dr., Pleasanton, CA 94588; Tel: 925-847-5408; Fax: 925847-5322; E-mail: grace.jone@lpp.org.

Copyright( 2000 Acadeny of Managed Care Pharmacy, Inc. All rights reserved.

\section{by Grace T. Jone and Anthony P. Morreale}

7 he treatment and management of peptic ulcer disease has become simpler over the past decade as more is understood about Helicobacter pylori (H. pylori) and its elationship to duodenal and gastric ulcers. The 1994 National Institutes of Health (NIH) Consensus panel recommends eradication of $\mathrm{H}$. pylori for all infected persons with peptic ulcer disease. ${ }^{1}$ Eradication of $H$. pylori with triple therapy prevents future ulcer recurrences in the vast majority of cases; in infected individuals; such treatment is nearly curative compared to chronic acid suppression. Several cost analyses published recently show the financial benefits of preventing ulcer recurrences and reducing subsequent health care utilization..$^{2-5}$ However, none of these models or studies have examined patients who are already on long-term prophylaxis for presumed or clinically documented ulcers with the test-and-treat approach, or employed the use of convenient fingerstick antibody testing to determine $H$. pylori serology status. These patients are potentially at risk for symptomatic ulcer recurrences and gastrointestinal bleeding despite maintenance with $\mathrm{H}_{2}$ antagonists.

The most significant health care resources saved by treating $H$. pylori are additional outpatient office visits and medications for symptomatic recurrences, and costs associated with ulcer complications such as hospitalizations, endoscopy, and surgery. Data from several studies have shown that $H$. pylori eradication is less expensive than conventional $\mathrm{H}_{2}$-blocker $\left(\mathrm{H}_{2} \mathrm{~B}\right)$ therapy for peptic ulcer disease. ${ }^{7,8}$ However, the application of these results in current practice is lagging. ${ }^{9}$

We have identified patients on long-term $\mathrm{H}_{2}$-blocker therapy for ulcer symptoms or prophylaxis at the Veterans Affairs San Diego Healthcare System (VASDHS), and designed a decision-tree analysis to determine the cost benefit of $H$. pylori screening and eradication in infected patients from an integrated health care organization perspective. Our cost-benefit computer model is representative of certain health care systems and may function as a model to determine cost savings when implementing an $\mathrm{H}$. pylori testing and eradication program.

Several advances in technology and more convenient, shorter treatment regimens allow identification, treatment, and eradication of $H$. pylori in infected patients in a timely and, it is hoped, permanent fashion. In 1998 the Food and Drug Administration (FDA) approved two 10-day triple-lherapy regimens containing a proton-pump inhibitor and two antibiotics. 


\begin{tabular}{|c|c|c|}
\hline Variable & Rate $(\%)$ & Description \\
\hline Complication rate & 0.027 & $\begin{array}{l}\text { Rate of ulcer complications (hemorrhage, perforation, } \\
\text { or obstruction) associated with ulcer relapse }\end{array}$ \\
\hline Eradication rate & 0.86 & $\begin{array}{l}\text { H. pylori eradication rate following 10-day course } \\
\text { of clarithromycin, amoxicillin, and lansoprazole (CAL regimen) }\end{array}$ \\
\hline $\mathrm{H}_{2} \mathrm{~B}$ relapse rate & 0.28 & Ulcer relapse rate in patients on $\mathrm{H}_{2}$-blocker maintenance therapy \\
\hline HP-symptom rate & 0.25 & Rate of symptomatic occurrence in patients with $H$. pylori negative serology \\
\hline $\mathrm{HP}+$ recur rate & 0.73 & Ulcer recurrence rate in $H$. pylori positive patients \\
\hline $\mathrm{HP}+$ rate & 0.50 & Rate of VASDHS patients testing positive for H. pylori \\
\hline HP relapse rate & 0.037 & Ulcer relapse rate in patients following eradication of $H$. pylori \\
\hline
\end{tabular}

'VASDHS laboratory data, 1.997.

These are the shortest courses of eradication therapy that have received FDA approval. With the advent of low-cost $H$. pylori diagnostic fingerstick antibody tests, evaluation of serology status will be less painful and faster.

An $H$. pylori clinic can be specifically designed to identify, assess, and treat $H$. pylori in peptic ulcer patients. Several clinics managed by clinical pharmacists have been established and have demonstrated cost-effectiveness. ${ }^{10,11}$ Costs associated with establishing a pharmacist-managed clinic are included in this pharmacoeconomic model. This paper presents a computer model that can be used to analyze and justify a pharmacistmanaged $H$. pylori clinic.

\section{Methods}

\section{Decision Analysis}

A decision-tree analysis was established based on practice guidelines, published clinical probabilities, and costs representative of the VASDHS. 2, 12-13 (See Figure 1, page 387.) Two treatment strategies were evaluated at the decision node: continuing chronic $\mathrm{H}_{2} \mathrm{~B}$ therapy and evaluating $H$. pylori status and starting triple therapy. The outcomes for each strategy are based on eradication and ulcer recurrence rates from published studies and direct medical costs associated with drug therapy and treating recurrences.

\section{Patients}

When entered into the model, all patients are assumed to have a diagnosis of duodenal or gastric ulcer and to be receiving maintenance $\mathrm{H}_{2}$-antagonist therapy. Diagnosis may be provided by a gastroenterologist or a primary care practitioner based on an endoscopy, contrast study, or empiric evaluation of symptoms. Potential candidates for $H$. pylori screening were determined through a computerized search of pharmacy databases.
Approximately 900 patients were determined to be currently receiving cimetidine or famotidine for ulcer symptoms or prophylaxis as written in the patient instructions. Patients receiving $\mathrm{H}_{2}$ antagonists for gastroesophageal reflux were excluded. The approximate size of the prospective patient pool was confirmed by the identification of patients through International Classification of Diseases, Ninth Revision (ICD-9) codes for VASDHS inpatient and outpatient encounters for 1.997. Approximately 70 ICD-9 codes were used to identify peptic ulcer disease patients.

\section{Assumptions}

The computer model evaluates total health care costs for one year for each patient entering the model. Patients have not received prior $H$. pylori eradication therapy. Symptomatic patients return for nonroutine office visits; asymptomatic patients do not return. Patients are followed in the cost model until symptomatic cure, reevaluation for presence of ulcer by endoscopy, or ulcer complication. The cost for $\mathrm{H}_{2} \mathrm{~B}$ therapy was assumed to be for one year regardless of when symptoms recurred, because no good data appears to exist regarding when peptic ulcer symptoms return. The efficacy rate for retreatment after symptomatic recurrence was assumed to be the same as initial eradication rate. Good clinical studies examining retreament success rates appear to be lacking. Costs are direct medical costs based on accessible VASDHS costs or Health Care Financing Administration (HCFA) reimbursement. In a small percentage of patients, ulcer complications led to hospitalizations; an average length of stay at the VASDHS is five days. For consideration in establishing an $\mathrm{H}$. pylori clinic, all patients are evaluated and assessed in the clinic during the first year. All costs and outcomes incurred in the future have been discounted $5 \%$ each year to approximately calculate future monetary 


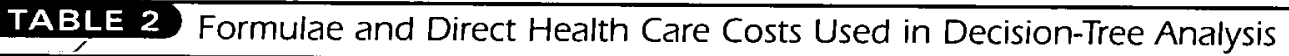

\begin{tabular}{|c|c|c|}
\hline Branch or Variable & Formula or Cost & Description \\
\hline Length of stay & LOS $=5$ days & $\begin{array}{l}\text { Estimated hospitalization length of } \\
\text { stay at VASDHS in } 1998\end{array}$ \\
\hline $\begin{array}{l}\text { Triple course of } \\
\text { treatment cost }\end{array}$ & TripleTX $=\$ 75$ & $\begin{array}{c}\text { Clarithromycin, amoxicillin, lansoprazole } \\
\text { 10-day course including drug cosis and } \\
\text { pharmacy dispensing fees }\end{array}$ \\
\hline Endoscopy cost & Endo $\cos t=\$ 500$ & Estimate by VASDHS gastroenterologists \\
\hline $\mathrm{H}_{2}$-blocker therapy & $\mathrm{H}_{2} \mathrm{~B} \cos \mathrm{t}=\$ 58$ & $\begin{array}{l}\text { Cimetidine or famotidine including annual } \\
\text { drug cost and pharmacy dispensing fees }\end{array}$ \\
\hline Daily cost of hospitalization & Hospcostdaily $=\$ 1,098$ & VASDHS inpatient charges per day in 1998 \\
\hline Office visit & $\$ 40$ & $\begin{array}{l}1998 \text { Health Care Financing Administration } \\
\text { reimbursement for physician office visit }\end{array}$ \\
\hline Serology cost & $\$ 10$ & Fingerstick serology kit or VASDHS laboratory cost \\
\hline Chronic $\mathrm{H}_{2} \mathrm{~B}$ cured & $\mathrm{H}_{2} \mathrm{~B} \cos \mathrm{t}+$ Office visit & Office visit for assessment and prescription renewal \\
\hline Persistent symptoms & $\mathrm{H}_{2} \mathrm{~B} \operatorname{cost}+$ Office cost + Endo cost & Peptic ulcer patients with persistent symptoms \\
\hline Ulcer complications & $\mathrm{H}_{2} \mathrm{~B} \cos \mathrm{t}+($ Hospcostdaily $*$ LOS $)+$ Endo cost & Gastrointestinal bleed, obstruction, perforation \\
\hline $\mathrm{HP}+$, cured & Triple IX cost + Serology + Office visit & $\begin{array}{l}\text { H. pylori positive patient with } \\
\text { no symptom recurrence }\end{array}$ \\
\hline $\mathrm{HP}+$, persistent symptoms & $\begin{array}{l}\text { TripleTX cost + Serology }+ \\
\text { Office visit + Endo cost }\end{array}$ & $\mathrm{HP}+$ patients with persistent symptoms \\
\hline Ulcer complications & $\begin{array}{l}\text { TripleTX cost }+ \text { Serology }+ \text { Office visit }+ \\
(\text { Hospcostdaily*LOS }+ \text { Endo cost }\end{array}$ & $\begin{array}{l}\mathrm{HP}+\text { patients with gastrointestinal bleed, } \\
\text { obstruction, or perforation }\end{array}$ \\
\hline HP Retreat cured & Serology $+($ Triple TX cost + Office visit $) * 2$ & $\begin{array}{l}\mathrm{HP}+\text { patients with symptom recurrence } \\
\text { and second course of triple therapy }\end{array}$ \\
\hline $\begin{array}{l}\text { HP Retreat, } \\
\text { Persistent symptoms }\end{array}$ & $\begin{array}{l}\text { Serology }+ \text { (TripleTX cost }+ \text { Office } \\
\text { visit) }{ }^{*}+\text { Office cost }+ \text { Endo cost }\end{array}$ & $\begin{array}{l}\text { HP+ patients with symptom recurrence } \\
\text { despite second course of triple therapy, } \\
\text { additional office visit necessary for reevaluation }\end{array}$ \\
\hline $\begin{array}{l}\text { HP Retreat, ulcer } \\
\text { complications }\end{array}$ & $\begin{array}{c}\text { Serology }+(\text { TripleTX cost }+ \text { Office } \\
\text { visit }) * 2+\text { Office cost }+(\text { Hospcostdaily } \\
\left.{ }^{*} \text { LOS }\right)+ \text { Endo cost }\end{array}$ & $\begin{array}{l}\mathrm{HP}+\text { patients with gastrointestinal bleed, obstruction, } \\
\text { or perforation; office visit to identify complication }\end{array}$ \\
\hline $\begin{array}{l}\mathrm{HP}+\text {, unsuccessful } \\
\text { eradication }\end{array}$ & TripleTX cost + Serology + Office visit & $\begin{array}{l}\text { HP+ patients, unsuccessful eradication, } \\
\text { no symptoms }\end{array}$ \\
\hline $\mathrm{HP}-$, symptoms absent & Serology + Office visit & $\begin{array}{l}\text { H. pylori negative patient, no recurrence } \\
\text { of symptoms, } \mathrm{H}_{2} \text {-blocker therapy discontinued }\end{array}$ \\
\hline HP-, symptoms resolved & Serology + Office visit + Office visit $+\mathrm{H}_{2} \mathrm{~B} \cos \mathrm{C}$ & $\begin{array}{c}\mathrm{HP}-, \mathrm{H}_{2} \text {-blocker restarted for recurrence } \\
\text { of symptoms }\end{array}$ \\
\hline HP-, persistent symptoms & $\begin{aligned} \text { Serology } & + \text { Office visit }+ \text { Office visit }+\mathrm{H}_{2} \mathrm{~B} \text { cost } \\
& + \text { Endo cost }+ \text { Office visit }\end{aligned}$ & $\begin{array}{l}\mathrm{HP}-\text {, persistent symptoms despite restart of } \\
\qquad \mathrm{H}_{2} \mathrm{~B} \text { therapy, reevaluation }\end{array}$ \\
\hline $\begin{array}{l}\mathrm{HP}- \\
\text { ulcer complications }\end{array}$ & $\begin{array}{l}\text { Serology + Office visit }+ \text { Office visit }+\mathrm{H}_{2} \mathrm{~B} \text { cost } \\
+(\text { Hospcostdaily*LOS })+\text { Endo cost }\end{array}$ & $\begin{array}{c}\mathrm{HP}-, \mathrm{H}_{2} \text {-blocker restarted, gastrointestinal bleed, } \\
\text { obstruction, perforation }\end{array}$ \\
\hline
\end{tabular}


TABLE 3 Costs Per Treatment Strategy Over Three Years (Net Costs, N=900)

\begin{tabular}{l|c|c|c|c|c}
\hline Year & $\begin{array}{c}\text { Chronic } \mathrm{H}_{2} \mathrm{~B} \\
\text { Tx Net Costs }\end{array}$ & $\begin{array}{c}\text { H.pylori Screening } \\
\text { Eradication Net Costs }\end{array}$ & $\begin{array}{c}\text { Cost } \\
\text { Difference }\end{array}$ & $\begin{array}{c}\text { Net Cost } \\
\left(\$ / \mathrm{pt}^{*} 900 \text { patients) }\right.\end{array}$ & $\begin{array}{c}\text { Cost } \\
\text { (subtracting clinic cost } \\
\text { of } \$ 90,000 \text { for year 1) }\end{array}$ \\
\hline 1. & $\$ 290$ & $\$ 1.46$ & $\$ 144$ & $\$ 129,600$ & $\$ 39,600$ \\
\hline 2 & $\$ 551$ & $\$ 215$ & $\$ 336$ & $\$ 302,400$ & $\$ 212,400$ \\
\hline 3 & $\$ 785$ & $\$ 276$ & $\$ 509$ & $\$ 458,100$ & $\$ 368,100$ \\
\hline
\end{tabular}

value against year one (base year), established as 1998.

\section{Clinical Probabilities}

All recurrence rates were based on data from published studies. ${ }^{2}$ If patients continue on long-term $\mathrm{H}_{2} \mathrm{~B}$ therapy, $28 \%$ will likely experience ulcer recurrence within six months. ${ }^{2}$ The majority of these patients are assumed to have an uncomplicated recurrence and to undergo an endoscopy and an additional office visit for symptom evaluation. An estimated $2.7 \%$ of patients in whom ulcers recur will experience a complicated ulcer such as gastrointestinal bleeding, perforation, or obstruction and require hospitalization. ${ }^{2}$ Table 1 (see page 384 ) shows clinical probabilities used in the decision analysis; Table 2 (see page 385) describes the formulae employed.

The rate of $H$. pylori seropositivity for patients with known or suspected ulcer at the VASDHS was approximately $50 \%$, based on 1997 laboratory serology data. Therefore, of the total patients evaluated for $H$. pylori, half are assumed to test positive. Seropositive patients are started on an FDA-approved 1.0-day triple-agent course consisting of clarithromycin $500 \mathrm{mg}$ twice a day, amoxicillin $\mathrm{lg}$ twice a day, and lansoprazole $30 \mathrm{mg}$ twice a day (CAL). If a patient is either penicillin-allergic or taking medications that interact with clarithromycin, metronidazole $500 \mathrm{mg}$ twice a day is substituted. The eradication rate for the 10 -day CAL regimen is reported as $86-88 \% .^{14,15}$

Compliance may be improved for short 10-day courses of therapy. The vast majority of patients are presumed to be symptom-free following triple eradication therapy. Only an estimated $3.7 \%$ experience ulcer recurrence after successful eradication. ${ }^{2}$ Patients undergo retreatment with triple therapy in the event of an ulcer recurring. For the remaining 50\% of patients who are $H$. pylori seronegative, $\mathrm{H}_{2}$-antagonist therapy will be reevaluated and discontinued if possible. Of these patients, $25 \%$ will experience a return of dyspeptic symptoms and require a subsequent office visit and endoscopy for reevaluation of peptic ulcer diagnosis.

\section{Costs}

Costs of treatment for each arm were determined for one year. All costs are based on VASDHS hospital and pharmacy direct costs that were accessible. Indirect costs, such as fixed costs, facility maintenance, loss of patient productivity, or clinic supplies were excluded from the study for simplicity. Costs for outpatient office visits were derived from 1998 HCFA reimbursement because VASDHS data were not accessible. Endoscopy procedure costs at the VASDHS were not accessible; an estimate by VASDHS gastroenterologists was utilized. In determining variable costs, we have tried to maintain costs consistent with the VASDHS model as best as can be estimated or calculated. Drug-therapy costs included VA drug acquisition costs and a $\$ 5$ dispensing fee per medication. H. pylori serology diagnostic fingerstick kits are available for approximately $\$ 1.0$ per kit. VA laboratory costs for $H$. pylori antibody testing were similarly approximately $\$ 10$. Renewal of chronic $\mathrm{H}_{2} \mathrm{~B}$ therapy required at least one office visit for annual renewal of the prescription. The cost to implement a program to identify eligible patients, determine $H$. pylori serology, reevaluate long-term $\mathrm{H}_{2}$-antagonist treatment, initiate $H$. pylori eradication therapy, and perform follow-up is primarily the cost for a clinician to staff the clinic on a full-time basis for one year. We have chosen as the designated clinician a pharmacist, whose salary and benefits cost the medical facility $\$ 90,000$ annually in 1998. All costs are listed in Table 3 (above).

\section{Factors Not Addressed}

Antibiotic complications were assumed to be minimal. Antibiotic resistance is not presumed to be a significant factor because the regimen uses dual antibiotics. Gastric cancer is not addressed; we assumed that the primary care provider evaluated risk at the time of original diagnosis. Presence of $H$. pylori has been linked to increased incidence of gastric cancer. Treating $H$. pylori infection may decrease gastric cancer risk and therefore contribute to improving patient care and lowering long-term health care costs. Endoscopy complications were not included.

\section{Results}

Figure 1 is a pharmacoeconomic tree, developed using the DATA 3.0 TreeAge computer program, that illustrates costs associated with drug cost, routine outpatient office visits, and cost of treating ulcer recurrences for each alternative arrange- 


\section{FIGURE $1 \longdiv { \text { Decision-Tree Analysis } }$}

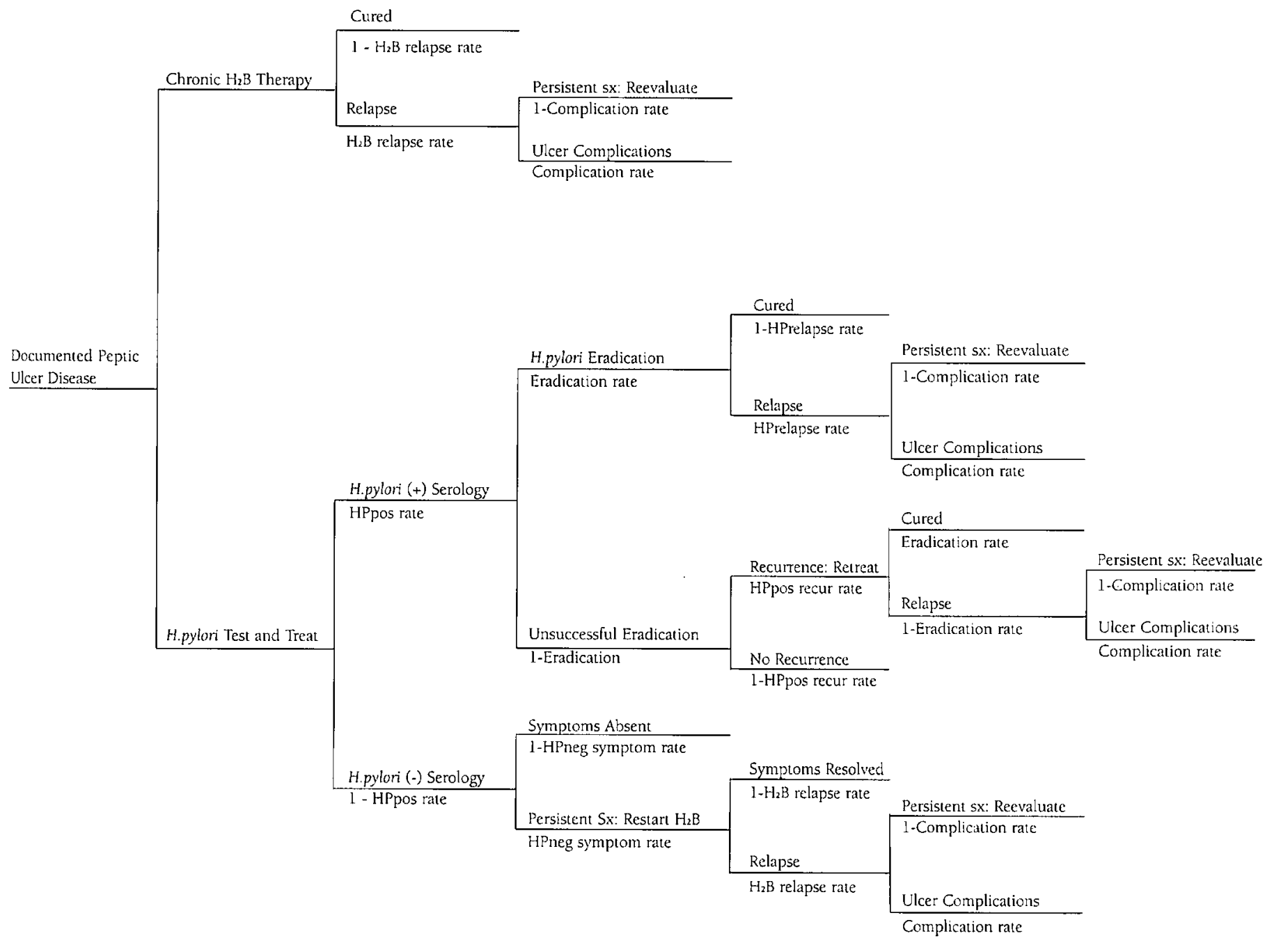

ment. ${ }^{16}$ Figure 2 (see page 388) depicts the relationship between the costs of drug therapy, office visits, and ulcer recurrences and the overall cost for the initial year of therapy for each treatment $\mathrm{arm}$. The cost of ulcer recurrences represents the principal health care expense for peptic ulcer disease management.

Evaluating $H$. pylori serology and treating infected individuals with CAL therapy ( $\$ 146$ per patient) was approximately two times as cost effective per patient during the initial year, compared with treatment with conventional $\mathrm{H}_{2}$-blocker maintenance ( $\$ 290$ per patient). These financial benefits can be expected to persist because evaluated patients will not consume health care dollars for future ulcer recurrences. Assuming that all patients are evaluated by the H. pylori clinic during the initial year of program implementation, the cumulative cost-savings for each year can therefore be calculated as the cost of con- ventional $\mathrm{H}_{2}$-antagonist therapy minus the cost of assessing and treating $H$. pylori positive patients and the cost to treat patients in the treat-and-test arm who continue to experience symptoms. Table 3 (see page 386) shows cumulative cost savings over a three-year period for 900 patients who enter the computer model, assuming no change in dollar present value or change in patient population size.

Cost savings after implementation of an $H$. pylori clinic is $\$ 368,100$ after three years. This cost savings represents a reduction in antisecretory agents and outpatient physician and gastroenterologist visits for symptoms, and fewer days of hospitalization for ulcer complications.

One-way sensitivity analyses were performed to evaluate the effect of variations in clinical probabilities and costs. The cost of testing and treating was cost-effective across a broad range of 

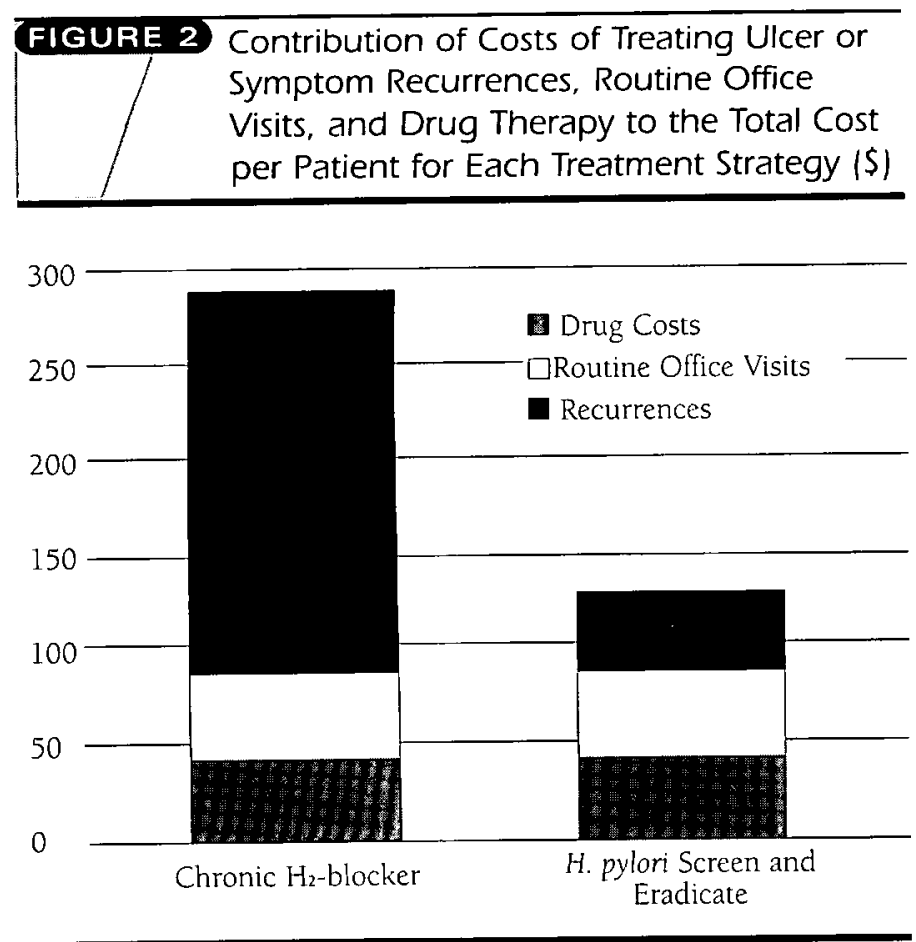

cost and probability estimates. Threshold values were determined for four factors that could have marginal impact on cost savings: $\mathrm{H}_{2} \mathrm{~B}$ relapse rate $(3.9 \%), \mathrm{H}$. pylori eradication rate $(27 \%)$, H. pylori relapse rate $(53 \%)$, and serology cost $(\$ 155)$. Beyond these values, $H$. pylori screening and testing would not be cost effective. Evidently, for the economic benefits of $H$. pylori testing and eradicating to be overcome, the difference between the variable and the base case value employed in the computer model must be tremendous.

\section{Discussion}

Although clinicians are faced with several alternatives to eradicate $H$. pylori, few regimens meet the criteria of being simple, inexpensive, effective, and using formulary agents. The FDAapproved 10-day CAL regimen meets all these criteria at the VASDHS and has been shown to be extremely efficacious clinically. ${ }^{14,15}$ Patient compliance and tolerance can be expected to significantly improve with this short course of treatment. The results of our cost modeling are consistent with other published studies. Total health care expenses per patient are lower than that of similar treatment strategies in other studies, a fact that may reflect lower drug costs at VA facilities compared with other medical centers

Assessing $H$. pylori status and treating infected individuals may be a standard of practice that can be improved upon at our institution. An $H$. pylori program could help primary care providers identify and treat appropriate candidates. Our costbenefit model takes into account direct medical costs associat- ed with implementing such a program in an integrated health care organization environment. The long-term $\mathrm{H}_{2}$-antagonist therapy arm represents the current state of patients with peptic ulcer disease. The alternate arm represents $H$. pylori testing and treating patients on long-term $\mathrm{H}_{2} \mathrm{~B}$ prophylaxis. The expected cost savings is the amount of health care utilization avoided with implementation of a coordinated $H$. pylori detection and eradication program. This cost-benefit computer model may have wide application to institutions where a number of patients continue to be medicated with $\mathrm{H}_{2}$-antagonists for peptic ulcer disease and escape evaluation for $H$. pylori infection This model is a tool that can be adapted to any particular organization and serve to cost-justify necessary staffing for clinic endeavors.

Our analysis shows that the economic advantage of screening and treating $H$. pylori is not affected by variations in such costs as medications, physician office visits, hospitalization, or endoscopy. Yet as shown by sensitivity analysis, cost savings associated with $H$. pylori eradication may be limited by $\mathrm{H}_{2-}$ antagonist relapse rate, $H$. pylori eradication rate, $H$. pylori relapse rate, and serology testing cost. However, for $H$. pylori screening and treating to not be cost-effective based on the decision tree, the range of values must vastly differ from the base case values employed in the computer model.

\section{Limitations}

Several factors that are applicable to the VA health care system, such as formulary restrictions, direct medical costs, and a predominantly male population, are not applicable to other health care systems. Therefore, conclusions reached here need to be adjusted and tailored to individual organizations. Our goal has been to improve the overall health and standard of care provided to VA patients in the treatment of peptic ulcer disease. The great majority of costs avoided were attributed to decreasing future peptic ulcer complications. A global integrated approach by upper health care management is required to appreciate the interventions that an $H$. pylori-dedicated clinic may provide. Financial outcomes and costs are affected by inflation; we have tried to lessen this limitation by discounting monetary costs incurred in the future. Most clinical probabilities were assumed from clinical studies. The difference between controlled clinical trial settings and realistic medicine situations may lead to differences in eradication rates, relapse rates, and other factors. By performing sensitivity analyses on all variables, we identified four factors most affected by variations in value.

\section{Conclusion}

Pharmacoeconomic modeling can be extremely helpful in making decisions about the creation or expansion of clinical programs. Our decision-tree analysis demonstrates the cost benefit of testing and treating patients receiving long-term $\mathrm{H}_{2}$ prophylaxis in an integraced health care setting and may be useful to 
justify additional staffing. In the end these models will need prospective follow-up studies to document their validity, but they do provide a useful review of the data that needs to be collected and some expected outcomes. We hope that this analysis will lead to the creation of more H. pylori testing and treatment programs to improve patient care and reduce health care spending.

\section{References}

1. NIH Consensus Development Panel. Helicobacter pylori in peptic ulcer disease. JAMA 1994; 272: 65-69.

2. Taylor JL et al. Pharmacoeconomic comparison of treatments for the eradication of H. pylori. Arch Intern Med 1997; 157: 87-97.

3. Offman JJ. Management strategies for $\mathrm{H}$. pylori-seropositive patients with dyspepsia: clinical and economic consequences. Ann Intern Med 1997; 126 (4): $280-316$.

4. Kozma CM et al. Defining strategies for peptic ulcer treatment: a Helicobacter pylori economic cost model. J Managed Care Pharm 1998; 4: 205-20.

5. O'Brien B et al. Cost effectiveness of Helicobacter pylori eradication for long-term management of duodenal ulcer in Canada. Arch Intern Med 1995; 155: 1958-64.

6. Imperial TF et al. A cost analysis of alternative treatments for duodenal ulcer. Ann Int Med 1995; 123: 665-72.
7. Vakil N, Fennerty MB. Cost effectiveness of treatment regimens for the eradication of Helicobacter pylori in duodenal ulcer. Am J Gastroent 1996; 91(2): 239-45.

8. Sonnenberg A, Townsend $W$. Costs of duodenal ulcer therapy with antibiotics. Arch Intern Med 1995; 1.55: 922-28.

9. Fendrick AM. Outcomes research in Helicobacter pylori infection. Aliment Pharmaco Ther 1997; 11 (Suppl 1): 95-101.

10. Morreale AP. Pharmacist-managed Helicobacter pylori clinic. AJHP 1995; 52: 183-85.

11. Patchin GM, Wieland KA, Carmichael JM. Six-months' experience with a pharmacist-run H. pylori treatment clinic. AJHP 1996; 53: 2081-82.

12. Soll AH. Medicai treatment of peptic ulcer disease: practice guidelines. JAMA 1996; 275(8): 622-29.

13. Walsh JH, Peterson WL. Drug therapy: the treatment of Helicobacter pylori infection in the management of peptic ulcer disease. NEJM 1995 ; 333(15): 984-91.

14. Krause $\mathrm{R}$ et al. 10 vs 14 day triple therapy with lansoprazole (Prevacid), amoxicillin, and clarithromycin in the eradication of Helicobacter pylori $(\mathrm{Hp})$. Gut 1997; 41(Suppl 1): Al01-02.

15. Wurzer $\mathrm{H}$ et al. Short-course therapy with amoxicillin-clarithromycin triple therapy for 10 days (ACT-10) eradicates Helicobacter pylori and heals duodenal ulcer. Aliment Pharmacol Ther 1997; 11: 943-52.

16. TreeAge Software, Inc. DATA 3.0 User's Manual, 1996. 